\title{
Sodium Hypochlorite as Fluorotic Dentin Pretreatment of Two-Step Self-Etch Adhesive with Silver Nanoparticle: Atomic Force Microscope and Adhesive Microtensile Bond Strength Evaluation
}

\author{
Ana-Josefina Monjarás-Ávila, ${ }^{1}$ Norma-Verónica Zavala-Alonso, ${ }^{1}$ \\ Gabriel Alejandro Martínez-Castañón, ${ }^{1}$ \\ Nuria Patiño-Marín, ${ }^{1}$ Daniel Silva-Herzog Flores, ${ }^{1}$ and Facundo Ruíz ${ }^{2}$ \\ ${ }^{1}$ Doctorate Program in Dental Science, Faculty of Dentistry, Autonomous University of San Luis Potosí, Av. Dr. Manuel Nava No. 2, \\ Zona Universitaria, 78290 San Luis Potosí, SLP, Mexico \\ ${ }^{2}$ Faculty of Science, Autonomous University of San Luis Potosí, Av. Dr. Salvador Nava S/N, Zona Universitaria, 78290 San Luis Potosí, \\ SLP, Mexico \\ Correspondence should be addressed to Norma-Verónica Zavala-Alonso; nveroza@fest.uaslp.mx
}

Received 21 February 2017; Revised 11 April 2017; Accepted 24 April 2017; Published 27 June 2017

Academic Editor: Victor M. Castaño

Copyright (C) 2017 Ana-Josefina Monjarás-Ávila et al. This is an open access article distributed under the Creative Commons Attribution License, which permits unrestricted use, distribution, and reproduction in any medium, provided the original work is properly cited.

\begin{abstract}
The objective of this work was to evaluate the effect of pretreatment with commercial sodium hypochlorite, 5.25\%, with a self-etch adhesive (Optibond Versa) in its original formula and with the incorporation of silver nanoparticles (NaAg) on fluorotic dentin. 240 human molars were classified according to fluorosis severity with Thylstrup-Fejerskov Index (TFI) and subdivided into three study subgroups according to the adhesive technique: (1) self-etch (SE) control subgroup; (2) NaOCl/SE subgroup; (3) NaOCl/SE $+\mathrm{NaAg}$ subgroup. The nanostructural characteristics were observed by AFM, $\mu$ TBS was tested, and hybrid layer formation was observed by SEM. One-way analyses of variance (ANOVA) and Tukey-Kramer post hoc tests were used. No statistically significant differences were found in roughness values in any of the subgroups and subgroups studied. Remnants of smear layer were detected in areas devoid of resin tags in SEM images of samples bonded with subgroup 2, in contrast to subgroup 3. No statistically significant difference between any of the results was found in $\mu \mathrm{TBS}$ and a greater number of adhesive failures were observed. The results show that the pretreatment technique of $5.25 \% \mathrm{NaOCl}$ and the incorporation of $\mathrm{NaAg}$ to the self-adhesive system do not produce a surface more adequate for a better adhesion.
\end{abstract}

\section{Introduction}

Dental fluorosis is defined as a dental malformation, which is believed to be caused by chronic ingestion of fluoride during the dental formation $[1,2]$. The prevalence of dental fluorosis (DF) can be as high as $80.9 \%$ in areas with fluoridated water and up to $42 \%$ in areas without fluoridated water [3-5]. The fluorotic enamel is characterized by hypermineralized outer surface and a subsurface hypomineralized. The pores in the enamel subsurface are occupied by water as well as proteins, which are retained due to the effect of excessive levels of fluoride on ameloblasts [6]. Mineralization patterns changes that occur in the enamel are not confirmed, while dentin patterns clearly exhibit increased mineralization. After the cessation of enamel secretion, a substantial variation of mineral content in dentin can be seen with occasional bands of interglobular dentin $[7,8]$. It has been reported that dentin with mild and moderate fluorosis is significantly more susceptible to tooth decay, in contrast with mild and moderate enamel fluorosis which is more resistant to decay [9]. Adhesion success to hard 
tissues is a fundamental requirement prior to placement of materials such as composites. The dentinal adhesives have evolved rapidly in recent years. The self-etching system has proven to be as effective as phosphoric acid when applied to normal enamel and mild fluorosis, but less effective than phosphoric acid when applied over moderate and severe enamel [10]. However, studies on fluorotic dentin show the opposite and it has been shown that self-etching systems are more effective than phosphoric acid to be placed on fluorotic dentin [11]. Attempting to improve the adhesive and antibacterial properties of self-etching systems and in order to prevent recurrence of cavities, it has been shown that higher adhesion forces are achieved when pretreatment of the dentine with sodium hypochlorite $5.25 \%$ commercial type is carried out; it is believed that these results, thanks to the generation of micro-roughness, are obtained on the surface dentin due to the removal of protein; this process called deproteinization has been indicated in teeth with cavity lesions of varying length and depth, fulfilling the function of adhesion promoter and acting as a bactericide and bacteriostatic agent as well. However, these evaluations have been carried out only on normal dentin but not on affected dentin with fluorosis. Also, several studies have demonstrated the highly bactericidal effect of silver nanoparticles ( $\mathrm{NaAg}$ ) on the main bacteria causing tooth decay. It has even been shown that when added to first adhesive 4th generation, bonding properties to the dentin are not affected [1215]. In our literature search, we found no studies where the effect of the incorporation of $\mathrm{NaAg}$ to 5th-generation self-etching primer on the mechanical properties, bonding, nanostructure, bactericides and cytotoxicity of normal and fluorotic dentin was analyzed. Therefore, the aim of this study is to evaluate the effect of using commercial sodium hypochlorite $5.25 \%$ prior to application of a two-step self-etch adhesive in its original formula and with the addition of silver nanoparticles on the surface topography and microtensile bond strength of fluorotic dentin. The hypothesis to be tested was as follows: the dentin pretreatment with $5.25 \%$ sodium hypochlorite and the incorporation of $\mathrm{NaAg}$ to the selfetching system improve the topography, mechanical, and adhesive properties of the dentin affected by fluorosis.

\section{Materials and Methods}

2.1. Collection and Sample Preparation. Patients undergoing premolar extractions at hospitals and private clinics for periodontal and orthodontic reasons, aged between 19 and 32 years, were asked to donate their cavity-free extracted teeth. An informed and voluntary written consent was obtained from the subjects prior to clinical examination. Autonomous University of San Luis Potosi Ethics Committee approved the research project grant CEIFE-030-016. Molars were collected from three different locations: (1) Ciudad Valles (San Luis Potosí, México), which has a water fluoride level between 0.1 and $0.6 \mathrm{ppm} \mathrm{F}$; (2) San Luis Potosi City (San Luis Potosí, México) with a natural fluoride level between 0.7 and 2 ppm F; and (3) Salitral de Carrera (San Luis Potosí, México) with natural fluoride level between 2 and $5 \mathrm{ppm}$. All samples were cleaned to remove remains of soft tissue, tartar, and blood (Ultrasonic Scaler Varios 350 NSK, IL, USA) and disinfected in an ultrasonic bath (Biosonic UC300115B, Colténe/Whaledent, OH, USA) with glutaraldehyde for 10 minutes, washed in running water, dried, and analyzed through a stereomicroscope for fluorosis severity according to the Thylstrup-Fejerskov Index (TFI). Two investigators did the classification, according to TFI, independently. TFI allows correlation between the clinical appearance of DF and the pathologic changes in human enamel and is normally the index of choice for the evaluation of fluorosis severity. The selected molars were divided into four groups of 60 samples each: control $(\mathrm{C})$ group, the mild $(\mathrm{Mi})$ group, the moderate (Mo) group, and the severe (Se) group.

2.2. Synthesis of Silver Nanoparticles and Incorporation into the Adhesive System. NaAg with spherical shape $(10.8 \pm 1.6 \mathrm{~nm})$ was synthesized by a simple precipitation method as reported by Espinosa-Cristóbal et al. [16]. Once synthesized, the NaAg, still dispersed in water (1070.0 ppm), was incorporated into the adhesive by means of mechanical mixing (stirring) in a 1:1 relation (final concentration of Nag: $535.0 \mathrm{ppm}$ ) with the help of a disposable applicator.

2.3. Sample Preparation. All molars were stored for no more than one month in $1.0 \%$ aqueous chloramine solution (Sigma chemical, St. Louis, MO, USA) under cooling in distilled water until experimental procedures were performed. The occlusal enamel and tooth root were removed to expose the flat dentin surface; subsequently each occlusal surface was sectioned parallel to the long axis of the tooth by means of a water-cooled low-speed diamond saw (\#7910, medium size grain; Brasseler, Savannah, GA, USA) to obtain samples $3 \mathrm{~mm}$ in width. The dentin samples were mounted in acrylic blocks. The dentin surface of the blocks was flattened under water cooling using 600-grit $\mathrm{SiC}$ paper to produce a uniform dentin smear layer. Dentin samples for each study group $(n=20$ per group) were divided randomly into three subgroups for three self-etch techniques: (1) self-etch adhesive (SE) control; (2) pretreatment with $5.25 \%$ sodium hypochlorite + self-etch adhesive ( $\mathrm{NaOCl} / \mathrm{SE})$; (3) pretreatment with $5.25 \%$ sodium hypochlorite + self-etch adhesive with $\mathrm{NaAg}$ incorporated $(\mathrm{NaOCl} / \mathrm{SE}+\mathrm{NaAg})$. In this study, the commercial selfetch two-step adhesive (Optibond Versa, Kerr) was used for the adhesion technique; Table 1 shows its composition and manufacturer's instructions. Table 2 shows the adhesion techniques used for each of the study subgroups.

2.4. Atomic Force Microscopy (AFM). We followed the methods of Zavala-Alonso et al., 2011 [17]. All samples were evaluated at the same scan size $\left(50 \times 49.5 \mathrm{~mm}^{2}\right)$ by triplicate in different areas, all of them selected at random, and a mean value was obtained for each sample. The evaluations of dentin roughness and depth, diameter, and amount of dentinal tubule orifice were carried out using AFM (Nanosurf Easy Scan 2, SPM Electronics, Liestal, Switzerland) in contact mode with a silicon nitride (SiN) scanning rate of $49.5 \mu \mathrm{m} / \mathrm{s}$. The values used for the short cantilever were as follows: spring constant $0.1 \mathrm{~N} / \mathrm{m}$; resonant frequency $28 \mathrm{kHz}$; length $225 \mu \mathrm{m}$; mean width $28 \mu \mathrm{m}$; thickness $1 \mu \mathrm{m}$; tip height $14 \mu \mathrm{m}$; 
TABLE 1: Optibond Versa material composition and manufacturer's instructions.

Material composition

Primer

Monomers: glycerol phosphate dimethacrylate (GPDM) self-etching adhesive monomer.

Hydrophilic comonomers including mono- and difunctional methacrylate monomers.

Solvents: water, acetone, and ethyl alcohol.

Photoinitiator: camphorquinone (CQ) based.

Adhesive

Monomers: hydrophobic, structural, and cross-linking monomers.

Solvents: ethyl alcohol.

Photoinitiator: camphorquinone (CQ) based.

Fillers: 0.4-micron barium glass nanosilica.

Fluoride: sodium hexafluorosilicate.

Manufacturer's instructions

Bottle delivery: shake Optibond Versa ADHESIVE bottle briefly prior to dispensing. Dispense 1-2 drops of Optibond Versa PRIMER and Optibond Versa ADHESIVE into two separate clean wells. Replace cap immediately after dispensing. Wet applicator tip completely.

Indications for use

Direct bonding applications

(1) Prepare cavity. Pumice clean unprepared tooth structure with a fluoride-free cleaning paste; rinse thoroughly with water spray and air dry.

(2) Apply Optibond Versa PRIMER to the dentin surface using the disposable applicator brush. Scrub the surface with a brushing motion for 20 seconds.

(3) Air-thin for 5 seconds with medium air pressure.

(4) Shake Optibond Versa ADHESIVE bottle briefly. Apply Optibond Versa ADHESIVE to the dentin surface with light brushing motion for 15 seconds.

(5) Air-thin for 5 seconds.

(6) Light-cure for 10 seconds.

(7) Apply composite according to manufacturer's instructions for use.

TABLE 2: Adhesion techniques for each study subgroup.

(1) Subgroup SE (control)

(2) Subgroup $\mathrm{NaOCl} / \mathrm{SE}$

(3) Subgroup $\mathrm{NaOCl} / \mathrm{SE}+\mathrm{NaAg}$
Primer of adhesive system Optibond Versa (SE) was applied with microbrush rubbing the surface of the dentin for 20 seconds as indicated by the manufacturer's instructions.

$5.25 \% \mathrm{NaOCl}$ to dentine surface was applied, rubbing for one minute, and then dried with absorbent paper and SE was applied for 20 seconds as explained above.

Dentine surface with $5.25 \% \mathrm{NaOCl}$ rubbing for one minute and then drying with absorbent paper. Placed on a tray $5 \mu \mathrm{L}$ of SE and $5 \mu \mathrm{L}$ silver nanoparticle solution were added $0.1 \%$ (Martínez-Castañon, 2008); the mixture was brought to the dentin surface by rubbing with a microbrush for 20 seconds. and radius $<10 \mathrm{~nm}$. A calibration grid of silicon oxide on a silicon substrate (Nanosurf AG, CH-4410, SPM Electronics, Liestal, Switzerland) with $X Y$ periodicity of $10 \mu \mathrm{m}$ and a $Z$ height of $119 \mathrm{~nm}$ was used to calibrate the instrument before the evaluation. The dentin surface roughness (DSR) was quantified using $R_{\mathrm{a}}$ and $D_{\mathrm{t}}$ parameters. $R_{\mathrm{a}}$ (roughness average) represents the arithmetical mean of the absolute values of the scanned surface profile. $D_{\mathrm{t}}$ represents the diameter of dentinal tubule orifice. $D_{t}$ was measured by Nanosurf Easy Scan 2 software. Six dentinal tubules orifices were located for each sample, each diameter was measured in $\mu \mathrm{m}$, and the results are expressed by mean and standard deviation for each experimental group.
2.5. Microtensile Bond Strength Test ( $\mu$ TBS). The occlusal enamel of the teeth was removed to expose the flat dentin surface. For this test the teeth were divided into 3 groups, healthy dentin, mild fluorosis dentine, and moderate fluorosis dentine. For each subgroup the study technique mentioned above in Table 1 was applied. After the adhesive (Optibond Versa, Kerr adhesive system) was applied with a disposable applicator to all samples and the excess was removed with air thinning for 5 seconds with medium air pressure, then a lightcuring unit (Cromalux-E, Meca-Physik Dental Division; Rastatt, Germany) was used for $20 \mathrm{sec}$ with a light output of $600 \mathrm{~mW} / \mathrm{cm}^{2}$; a $6 \mathrm{~mm}$ high resin composite crown was placed (Tetric ${ }^{\circledR}$, Ivoclar Vivadent, NY, USA) for each tooth; 
four increments approximately $1.5 \mathrm{~mm}$ thick were applied; each increment was light cured for $40 \mathrm{sec}$.

After storing the specimens in water at $37^{\circ} \mathrm{C}$ for $24 \mathrm{~h}$, each tooth was sectioned perpendicular to the bonded interface to obtain beam-shaped strips with a surface area of $1.0 \pm$ $0.2 \mathrm{~mm}^{2}$. A total of 90 samples were obtained (30 per each group); for this test the severe fluorosis group was excluded, due to the absence of dental organs diagnosed with this degree of fluorosis. Each specimen was carefully examined under a stereomicroscope (SZ-PT Olympus, Tokyo, JAP) at $\times 10$ and in order to eliminate stress concentrators, specimens with irregular fracture path that propagated away from the interface were discarded. Each specimen was attached to a Universal Testing Machine (Advanced Force Gauge, Mecmesin, West Sussex, UK) with a cyanoacrylate adhesive (Zapit, DVA, Corona, CA, USA) and then subjected to tensile forces at a crosshead speed of $1 \mathrm{~mm} / \mathrm{min}$; values were calculated in MPa. After that a stereomicroscope (SZPT Olympus, Tokyo, JAP) was used to classify the failure mode in one of the following categories: (a) adhesive if the failure occurred entirely within the adhesive interfacial zone; (b) cohesive if the failure occurred exclusively within the composite or within the dentin; and (c) mixed if the failure continued from the adhesive into either composite or dentin.

2.6. Scanning Electron Microscopy (SEM) Evaluation. Two beam-shaped strips of each study technique (prepared as described in Microtensile Bond Strength Test) were used for this observation. Each specimen was polished using 600grit silicon carbide paper disks to produce smooth polished surfaces. The slab was held at the resin composite, etched with $37 \%$ phosphoric acid gel for $15 \mathrm{sec}$, rinsed for $30 \mathrm{sec}$, and dried with oil-free air with a knob. The slabs were immersed in $5.25 \%$ sodium hypochlorite solution for $20 \mathrm{~min}$, washed thoroughly under running water for $5 \mathrm{~min}$, and then immersed in ascending concentrations of ethanol $(50 \%, 70 \%$, and $90 \%$ ) for $20 \mathrm{~min}$ each and $100 \%$ for $1 \mathrm{hr}$. The samples were fixed with double-faced stickers on the specimen holder and gold sputtered (S150A sputter coater, Edwards; London, $\mathrm{UK}$ ) to render the samples electrically conducting, using a very thin layer of gold. The samples were examined using SEM (JEOL JSM-6510 Tokyo, JAP), operated at $10 \mathrm{kv}$. The resin/dentin interface was examined at $\times 1500$.

2.7. Statistical Analysis. All data is expressed by mean and standard deviation. The Shapiro-Wilks and Brown-Forsythe methods were used to test the distribution of variables. Oneway analyses of variance (ANOVA) and Tukey-Kramer post hoc tests were used to examine differences in roughness, depth, diameter and quantification of dentinal tubule orifices (AFM), and tensile bond strength among the groups of dentine and among the subgroups with adhesive system. Chi-square analyses were performed to compare the failure modes in the groups. Two-way ANOVA factorial analysis was performed to compare the tensile bond strength in the groups. The JMP program, version 10.0 (SAS Institute, Cary, NC, USA), and Stata version 11.0 (Stata Corp LP, College Station, TX, USA) were used for statistics analysis. $p<0.05$ was considered significant.

\section{Results}

3.1. AFM Surface Characterization. AFM images for healthy dentin surfaces are shown in Figures 1(a)-1(c). Figure 1(a) that represents the control subgroup was the one observed with a greater number of open dental tubules, followed by subgroup 3 ; subgroup 2 was the one observed with more obliterated tubules. Figures 2(a)-2(c) illustrate a mild fluorosis dentin surface treated with three study techniques. The three images are shown to be very similar although Figure 2(b) is probably showing higher quality in the intertubular dentine. Figures 3(a)-3(c) illustrate a moderate fluorosis dentin surface treated with three study techniques. Figure 3(c) showed the largest number of open tubes followed by Figure 3(b) and then Figure 3(a). Figures 4(a)-4(c) illustrates a severe fluorosis dentin surface treated with three study techniques. The three figures are very similar, showing a large number of obliterated and elongated dentinal tubules.

\subsection{Roughness, Depth, Diameter, and Amount of Dentinal} Tubules Parameters. Table 3 shows the mean roughness of study groups after different self-etching techniques; it is noted that for the healthy group roughness decreases in subgroups 2 and 3 compared to control subgroup 1; the same trend is observed in the severe group where the roughness decreased in subgroup 3 with respect to the subgroup control. In the other study groups is a trend to increased roughness of subgroups 2 and 3 compared to control subgroup 1. However, no significant statistical difference was found.

Table 4 shows in all the study groups increased depth in subgroups 2 and 3 in reference to control subgroup 1, except for the healthy group subgroup 3 , which decreases in depth in reference to control subgroup 1, which was observed. Statistically significant difference was found in mild subgroup 2 like moderate and severe subgroup 3 in reference to the control subgroup.

In Table 5, it was found that there is, in all study groups, a tendency to increase the diameter of the dentinal tubules in subgroups 2 and 3 compared with control subgroup 1, except for subgroup 2 healthy group where there was a decrease in diameter; however, no significant statistical difference was found.

Table 6 shows the amounts of dentinal tubules found in an area of $50 \mathrm{um}^{2}$ after being treated with different self-etching techniques; it can be seen that in the mild, moderate, and severe study groups there is a tendency to lower the amounts of tubules in subgroups 2 and 3 in reference to control subgroup 1, unlike the healthy study group in which an increased amount of tubules was observed in subgroups 2 and 3 compared to control subgroup 1; however no statistically significant difference was found.

3.3. Microtensile Bond Strength ( $\mu$ TBS). The results of the microtensile bond strength test are summarized in Table 7 including means, standard deviations, and number of specimens. The $\mu$ TBS in healthy subgroup 2 decreased and subgroup 3 increased, both compared with control subgroup 1. Mild subgroups 2 and 3 decreased in $\mu$ TBS compared with control subgroup 1 . For moderate subgroup 2 the $\mu$ TBS 


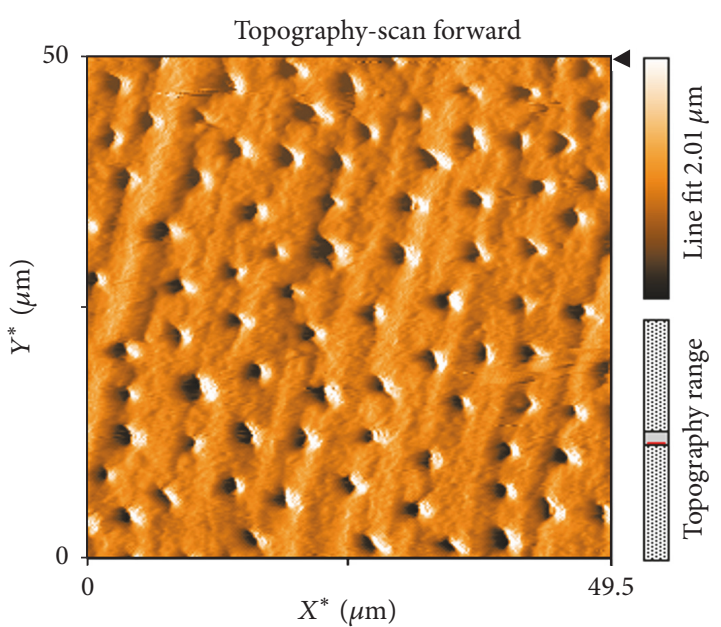

(a)

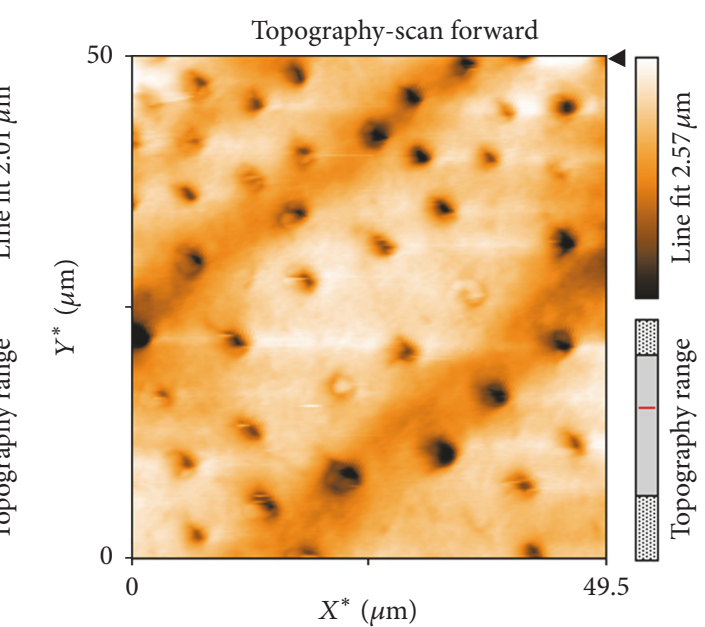

(b)

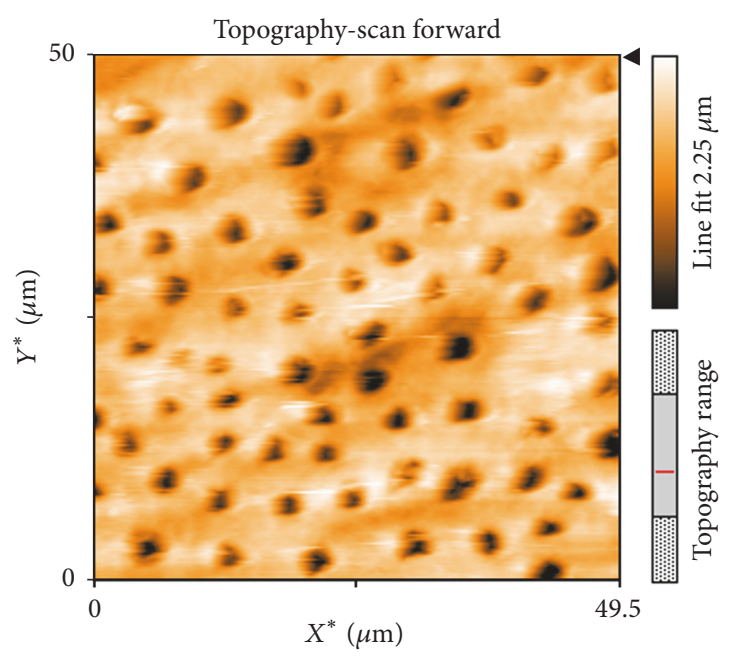

(c)

FIGURE 1: AFM images for healthy dentin surfaces treated with the techniques: (a) self-etch primer (SE), (b) pretreatment sodium hypochlorite commercial and self-etch primer $(\mathrm{NaOCl} / \mathrm{SE})$, and (c) pretreatment sodium hypochlorite commercial and self-etch primer with silver nanoparticles $(\mathrm{NaOCl} / \mathrm{SE}+\mathrm{NaAg})$.

TABLE 3: Mean roughness $\left(R_{\mathrm{a}}\right)$ of study groups after different self-etching techniques.

\begin{tabular}{lcccr}
\hline $\begin{array}{l}\text { Subgroups } \\
\text { (self-etching techniques) }\end{array}$ & Healthy & Mild & Moderate & Severe \\
\hline (1) Self-etch (SE) & $390.83 \pm 101.04$ & $312.18 \pm 100.69$ & $296.14 \pm 103.87$ & $311.30 \pm 105.23$ \\
$(2) \mathrm{NaOCl} / \mathrm{SE}$ & $376.64 \pm 100.82$ & $335.55 \pm 100.11$ & $320.57 \pm 106.71$ & $372.28 \pm 105.54$ \\
$(3) \mathrm{NaOCl} / \mathrm{SE}+\mathrm{NaAg}$ & $361.94 \pm 100.53$ & $369.63 \pm 101.95$ & $357.48 \pm 104.24$ & $286.57 \pm 103.13$ \\
\hline
\end{tabular}

Results show means \pm SD expressed in nanometers.

TABLE 4: Mean depth of study groups after different self-etching techniques.

\begin{tabular}{lcccc}
\hline $\begin{array}{l}\text { Subgroups } \\
\text { (self-etching techniques) }\end{array}$ & Healthy & Mild & Moderate & Severe \\
\hline (1) Self-etch (SE) & $-2.11 \pm 0.71$ & $-1.56 \pm 0.61$ & $-1.62 \pm 0.47$ & $-1.68 \pm 0.59$ \\
$(2) \mathrm{NaOCl} / \mathrm{SE}$ & $-2.41 \pm 0.83$ & $-2.04 \pm 0.43^{*}$ & $-2.01 \pm 0.70$ & $-2.04 \pm 0.80$ \\
$(3) \mathrm{NaOCl} / \mathrm{SE}+\mathrm{NaAg}$ & $-2.06 \pm 0.32$ & $-1.96 \pm 0.67$ & $-2.03 \pm 0.41^{*}$ & $-2.70 \pm-1.91^{*}$ \\
\hline
\end{tabular}

Results show means \pm SD expressed in nanometers. An asterisk $(*)$ indicates a statistically significant difference $(p<0.05)$ with control subgroup by using ANOVA test. 


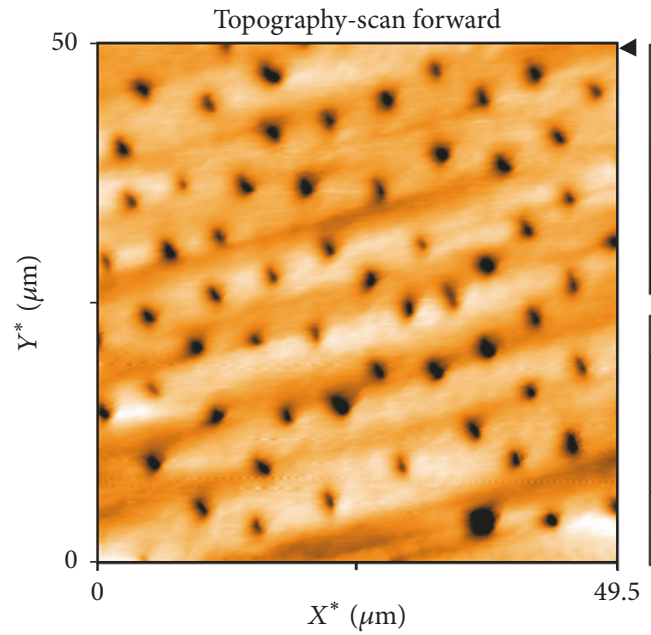

(a)

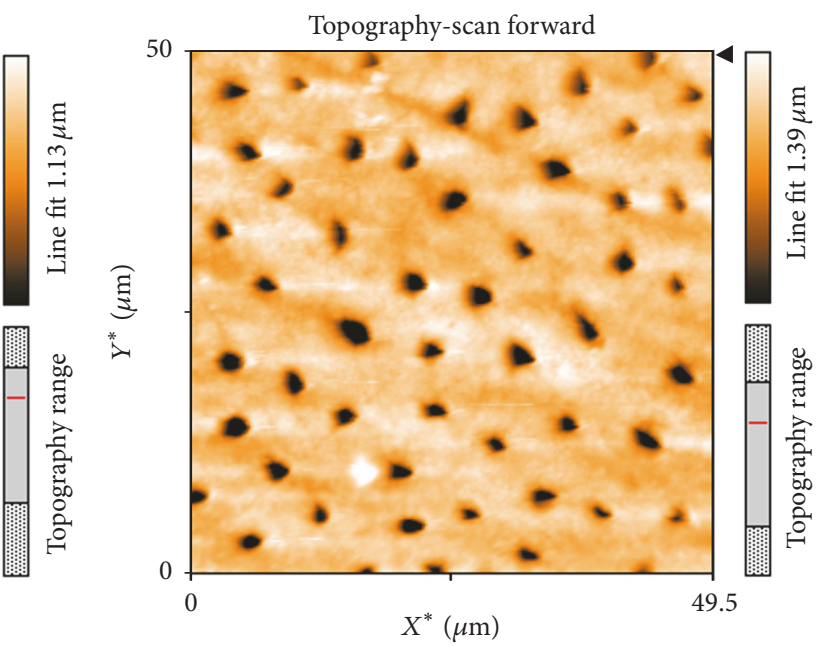

(b)

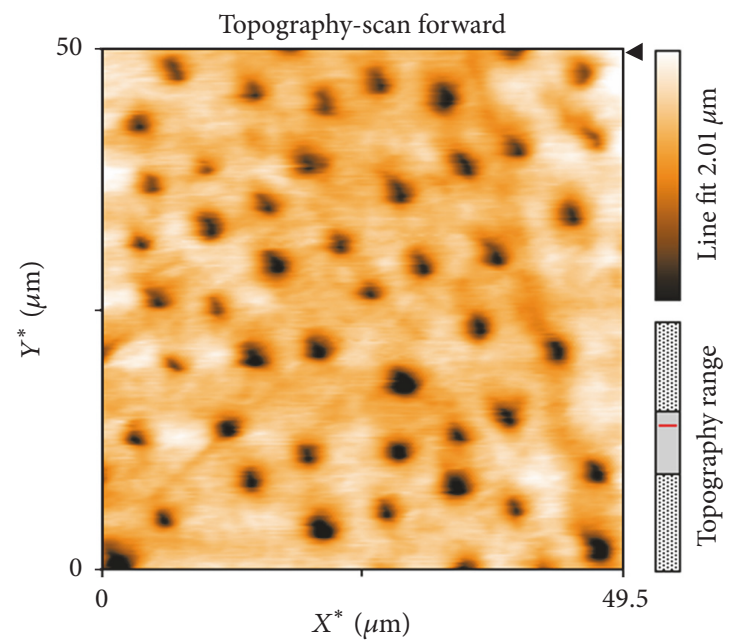

(c)

FIGURE 2: AFM images for mild fluorosis dentin surfaces treated with the techniques: (a) self-etch primer (SE), (b) pretreatment sodium hypochlorite commercial and self-etch primer $(\mathrm{NaOCl} / \mathrm{SE})$, and (c) pretreatment sodium hypochlorite commercial and self-etch primer with silver nanoparticles $(\mathrm{NaOCl} / \mathrm{SE}+\mathrm{NaAg})$.

TABLE 5: Mean diameter of dentinal tubules (nm) of the study groups after different self-etching techniques.

\begin{tabular}{lccrr}
\hline $\begin{array}{l}\text { Subgroups } \\
\text { (self-etching techniques) }\end{array}$ & Healthy & Mild & Moderate & Severe \\
\hline (1) Self-etch (SE) & $3.02 \pm 0.58$ & $2.83 \pm 0.54$ & $3.16 \pm 0.78$ & $3.10 \pm 0.54$ \\
$(2) \mathrm{NaOCl} / \mathrm{SE}$ & $2.75 \pm 0.71$ & $3.17 \pm 1.22$ & $3.45 \pm 0.86$ & $3.33 \pm 0.51$ \\
$(3) \mathrm{NaOCl} / \mathrm{SE}+\mathrm{NaAg}$ & $3.28 \pm 0.57$ & $2.97 \pm 0.57$ & $3.42 \pm 0.74$ & $3.31 \pm 0.95$ \\
\hline
\end{tabular}

Results show means \pm SD expressed in nanometers.

TABLE 6: Mean amount of dentinal tubules of the study groups after different self-etching techniques.

\begin{tabular}{|c|c|c|c|c|}
\hline $\begin{array}{l}\text { Subgroups } \\
\text { (self-etching techniques) }\end{array}$ & Healthy & Mild & Moderate & Severe \\
\hline (1) Self-etch (SE) & $32.73 \pm 28.41$ & $57.11 \pm 17.34$ & $45.80 \pm 17.53$ & $31.10 \pm 16.87$ \\
\hline (2) $\mathrm{NaOCl} / \mathrm{SE}$ & $42.70 \pm 24.29$ & $49.01 \pm 19.19$ & $40.05 \pm 25.86$ & $16.43 \pm 15.49$ \\
\hline (3) $\mathrm{NaOCl} / \mathrm{SE}+\mathrm{NaAg}$ & $41.25 \pm 26.12$ & $52.06 \pm 19.49$ & $31.03 \pm 23.84$ & $19.45 \pm 18.82$ \\
\hline
\end{tabular}

Results show means \pm SD expressed in amount in the area of $50 \times 50 \mathrm{um}$. 


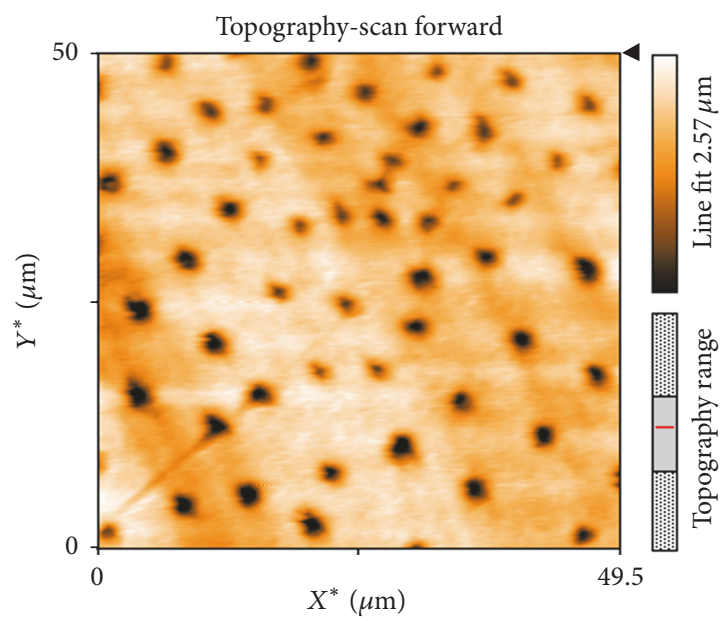

(a)

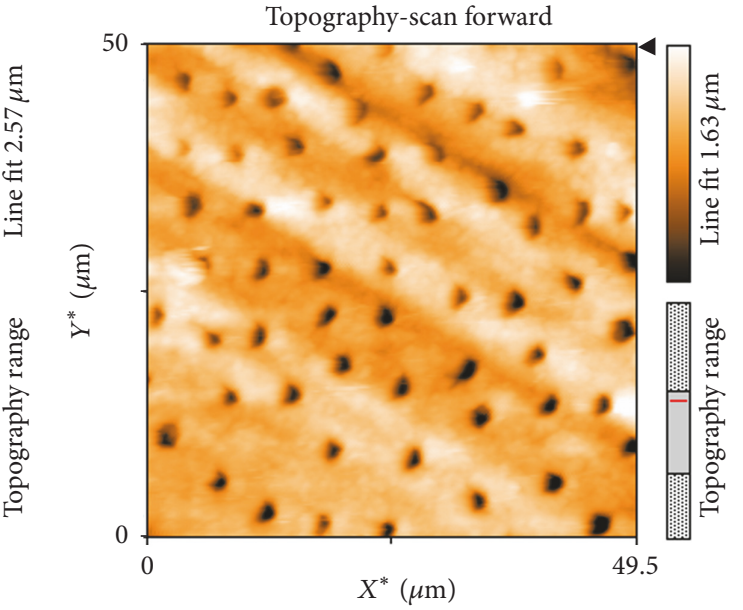

(b)

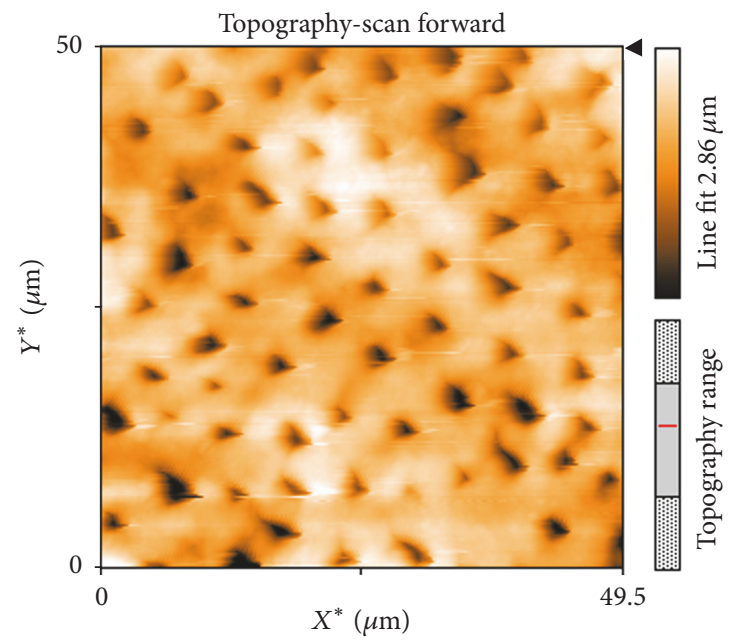

(c)

FIGURE 3: AFM images for moderate fluorosis dentin surfaces treated with the techniques: (a) self-etch primer (SE), (b) pretreatment sodium hypochlorite commercial and self-etch primer ( $\mathrm{NaOCl} / \mathrm{SE})$, and (c) pretreatment sodium hypochlorite commercial and self-etch primer with silver nanoparticles $(\mathrm{NaOCl} / \mathrm{SE}+\mathrm{NaAg})$.

TABLE 7: Mean microtensile bond strength ( $\mu$ TBS) of the study groups after different self-etching techniques.

\begin{tabular}{lccc}
\hline & Healthy & Mild & Moderate \\
\hline (1) $\mathrm{SE}($ control) & $15.62 \pm 8.89$ & $18.22 \pm 14.91$ & $11.22 \pm 8.58$ \\
$(2) \mathrm{NaOCl} / \mathrm{SE}$ & $11.30 \pm 7.79$ & $13.90 \pm 11.03$ & $12.81 \pm 12.78$ \\
$(3) \mathrm{NaOCl} / \mathrm{SE}+\mathrm{NaAg}$ & $22.37 \pm 21.72$ & $9.70 \pm 6.23$ & $8.46 \pm 4.81$ \\
\hline
\end{tabular}

Results show means \pm SD expressed in MPa.

was increased compared with control subgroup 1 but was decreased in subgroup 3; however, two-way ANOVA factorial analysis revealed that the tensile bond strength was not significantly different $(p<0.05)$ in the two factors; tooth (healthy dentin, mild fluorosis dentin, moderate, and severe Factor 1) and adhesive system (two-step self-etch, $\mathrm{NaOCl}$, and $\mathrm{NaAg}$ Factor 2). The interaction of the two factors was not significant $p=0.4089$. Table 8 shows the percentage of adhesive, cohesive, and mixed failure, using Chi-square analyses $(p<0.05)$, greater amounts of adhesive failure in healthy groups and greater amount of cohesive failure in mild and moderate groups were observed, and mixed failure was not found.

3.4. SEM Evaluation. Figures 5(a)-5(c) show SEM microphotographs of healthy group resin/dentin interfaces. Figure 5(a) shows the formation of the hybrid layer without resin tags in the interface, thin and continuing. Figure 5(b) shows smear layer incorporated within the hybrid layer, completely devoid of resin tags areas, which were observed. In Figure 5(c), 


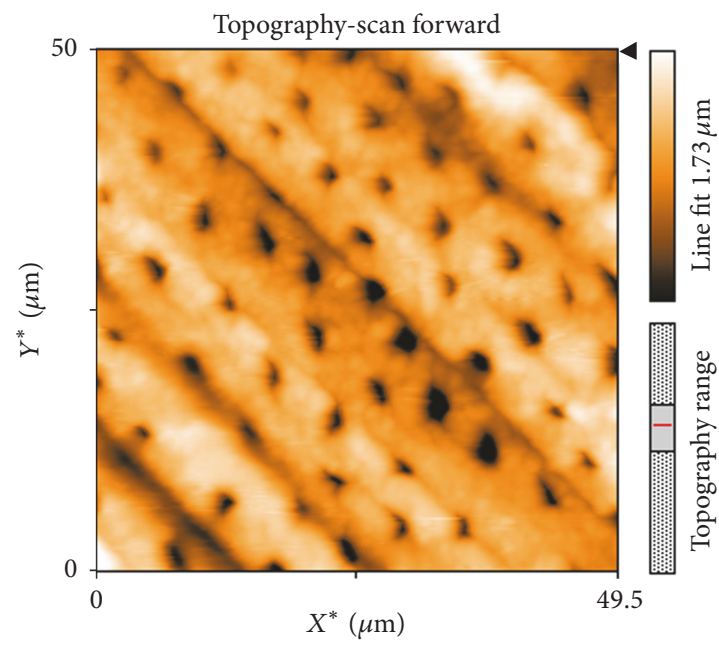

(a)

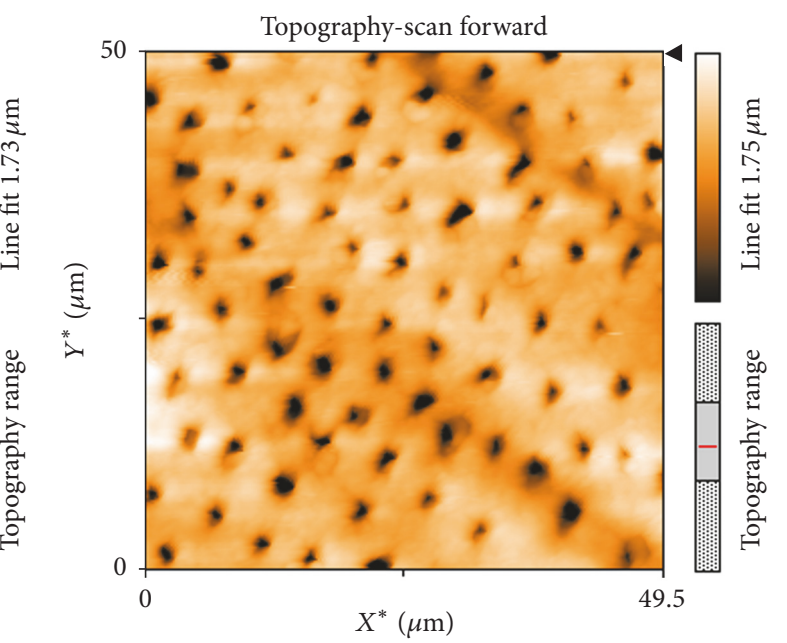

(b)

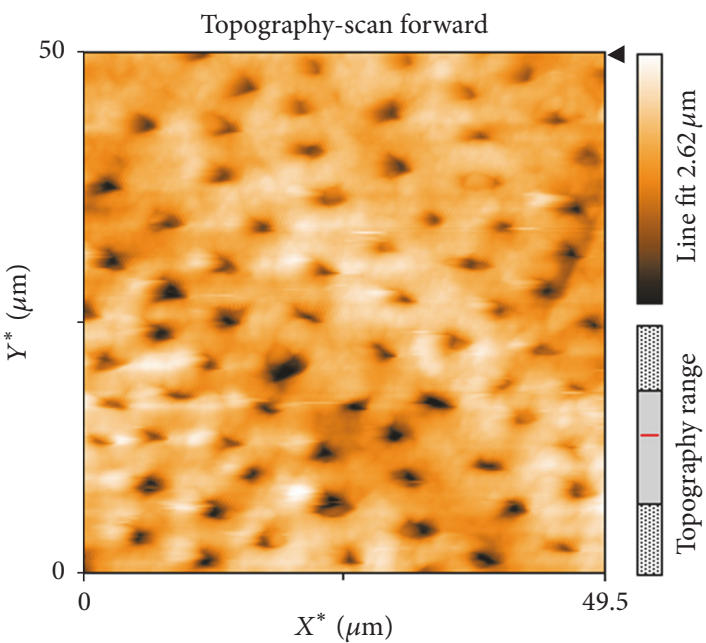

(c)

FIGURE 4: AFM 3D images for severe fluorosis dentin surfaces treated with the techniques: (a) self-etch primer (SE), (b) pretreatment sodium hypochlorite commercial and self-etch primer ( $\mathrm{NaOCl} / \mathrm{SE})$, and (c) pretreatment sodium hypochlorite commercial and self-etch primer with silver nanoparticles $(\mathrm{NaOCl} / \mathrm{SE}+\mathrm{NaAg})$.

TABLE 8: Failure mode of specimens of the study groups after microtensile bond test for each self-etching technique.

\begin{tabular}{|c|c|c|c|c|c|c|}
\hline & \multicolumn{2}{|c|}{ Adhesive } & \multicolumn{2}{|c|}{ Cohesive } & \multicolumn{2}{|c|}{ Mixed } \\
\hline & $N$ & $\%$ & $n$ & $\%$ & $n$ & $\%$ \\
\hline Healthy SE (control) & 9 & 90 & 1 & 10 & 0 & 0 \\
\hline Healthy $\mathrm{NaOCl} / \mathrm{SE}$ & 10 & 100 & 0 & 0 & 0 & 0 \\
\hline Healthy $\mathrm{NaOCl} / \mathrm{SE}+\mathrm{NaAg}$ & 9 & 90 & 1 & 10 & 0 & 0 \\
\hline Mild SE (control) & 8 & 80 & 2 & 20 & 0 & 0 \\
\hline Mild $\mathrm{NaOCl} / \mathrm{SE}$ & 7 & 70 & 3 & 30 & 0 & 0 \\
\hline Mild $\mathrm{NaOCl} / \mathrm{SE}+\mathrm{NaAg}$ & 8 & 80 & 2 & 20 & 0 & 0 \\
\hline Moderate SE (control) & 7 & 70 & 3 & 30 & 0 & 0 \\
\hline Moderate $\mathrm{NaOCl} / \mathrm{SE}$ & 6 & 60 & 4 & 40 & 0 & 0 \\
\hline Moderate $\mathrm{NaOCl} / \mathrm{SE}+\mathrm{NaAg}$ & 10 & 100 & 0 & 0 & 0 & 0 \\
\hline
\end{tabular}

Chi-square analyses $(p<0.05)$. 


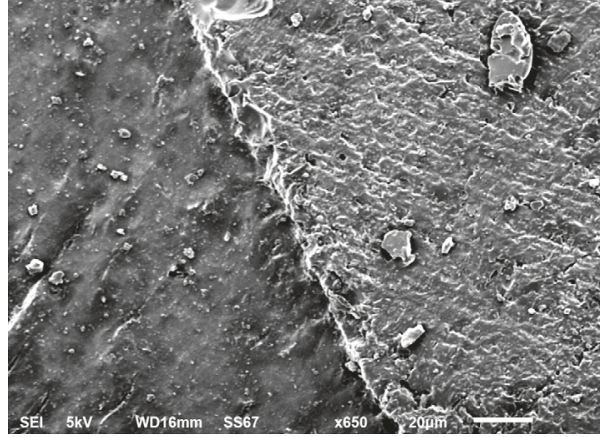

(a)

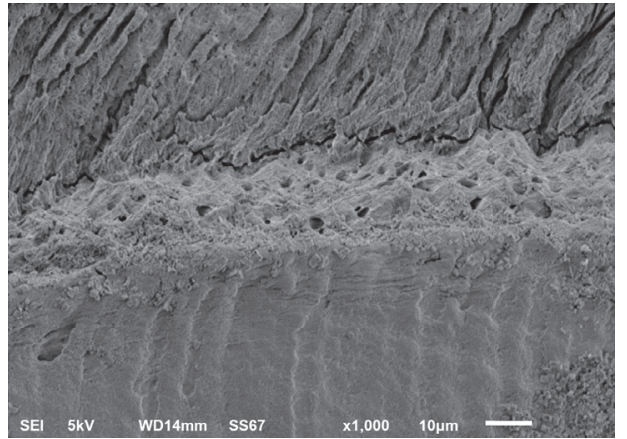

(b)

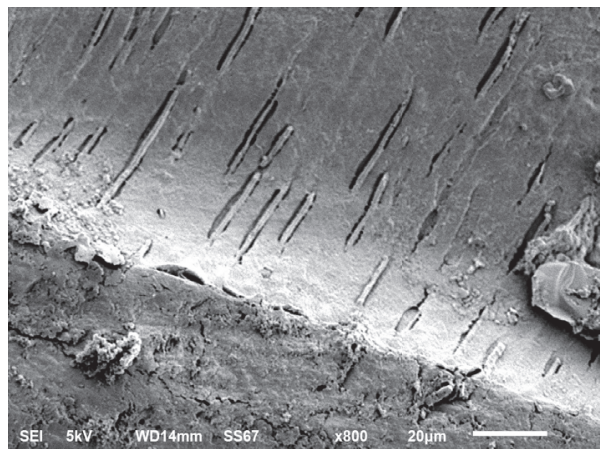

(c)

FIGURE 5: MEB microphotography of healthy dentin-resin interface treated with the following techniques: (a) self-etch primer (SE), (b) pretreatment sodium hypochlorite commercial and self-etch primer $(\mathrm{NaOCl} / \mathrm{SE})$, and (c) pretreatment sodium hypochlorite commercial and self-etch primer with silver nanoparticles $(\mathrm{NaOCl} / \mathrm{SE}+\mathrm{NaAg})$.

hybrid layer is infiltrated with adhesive fillers, long and short resin tags extending from it, but with some cracks in the bonding adhesive resin. Here there was complete dissolution of the smear layer with a very thin hybrid layer, which is not clearly seen.

Figures 6(a)-6(c) show SEM microphotographs of mild fluorosis resin/dentin interfaces. Figure 6(a) shows the absence of hybrid layer formation. Figure 6(b) shows a continuous hybrid layer over the entire interface is infiltrated with adhesive fillers, long resin tags extending from it. Figure 6(c) shows the formation of a thicker hybrid layer with numerous dentinal tubules; however these were devoid of resin tags.

Figures 7(a)-7(c) show SEM microphotographs of moderate fluorosis resin/dentin interfaces treated with the study techniques. Figure 7(a) observed that a defined hybrid layer over the entire interface is infiltrated with adhesive fillers, long resin tags extending from it. Figure 7(b) shows a dense and continuous layer over the entire interface, but with some cracks in the hybrid bonding adhesive resin. Figure 7 (c) shows extensions of dentinal tubules with resinous extensions with funnel-shaped characteristic of a dental substrate affected by fluorosis.

Figures $8(a)-8(c)$ show SEM microphotographs of severe fluorosis resin/dentin interfaces treated with the study techniques. Figure 8(a) shows a thin hybrid layer formed with a control group that loses slight continuity. Figure 8(b) shows dense and uniform and continuous hybrid layer formed. Figure 8(c) shows a hybrid layer very similar to the control group and with a thin continuity observed.

\section{Discussion}

To obtain an effective bond between the restorative material and dental tissue according to the self-etching approach, substrate infiltration by resin occurs simultaneously with the etching process. Features such as chemical composition of dentin and structural topographic variations, as well as the existence of the smear layer, exert direct influence on adherence to this tissue, as the main mechanism of adhesion is the micromechanical gear of the resin monomers on porous conditioned tooth surface [18]; the surface characteristics after the conditioning depend on the biological and morphological characteristics of the tissue [19]. Dentin consists of several structures such as tubules with cellular processes and fluid, peritubular and intertubular mineralized dentin consisting mainly of collagen and apatite deposits. Disturbances caused by age, injuries, and diseases such as cavities and dental fluorosis reflect information microstructural variations. In dental fluorosis, which is a malformation of the tooth caused by chronic ingestion of fluoride during the formation process $[1,2]$, it has been reported that dentine with mild and moderate fluorosis is significantly more susceptible to cavity formation [9]. The other studies performed with atomic force 


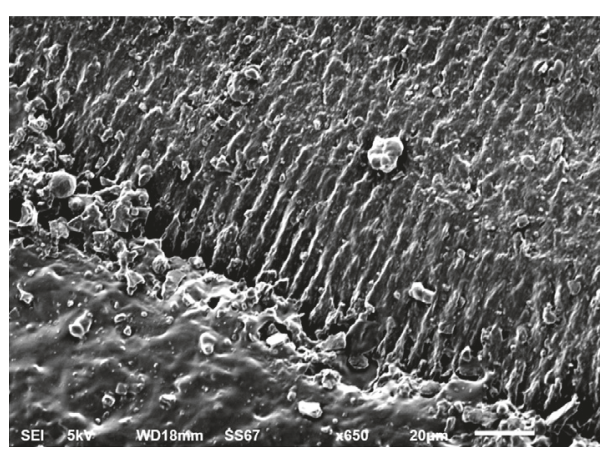

(a)

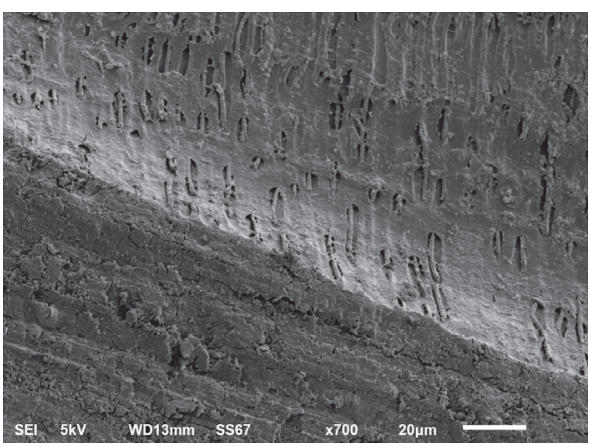

(b)

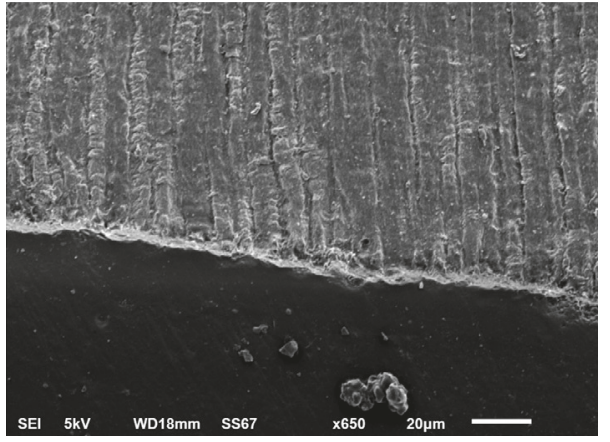

(c)

FIGURE 6: MEB microphotography of mild fluorosis dentin-resin interface treated with the following techniques: (a) self-etch primer (SE), (b) pretreatment sodium hypochlorite commercial and self-etch primer $(\mathrm{NaOCl} / \mathrm{SE})$, and (c) pretreatment sodium hypochlorite commercial and self-etch primer with silver nanoparticles $(\mathrm{NaOCl} / \mathrm{SE}+\mathrm{NaAg})$.

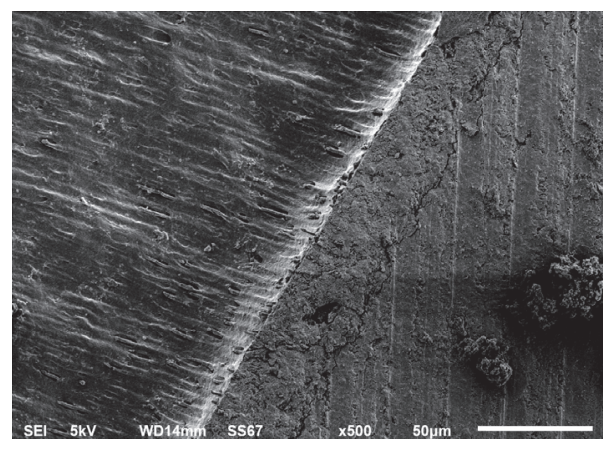

(a)

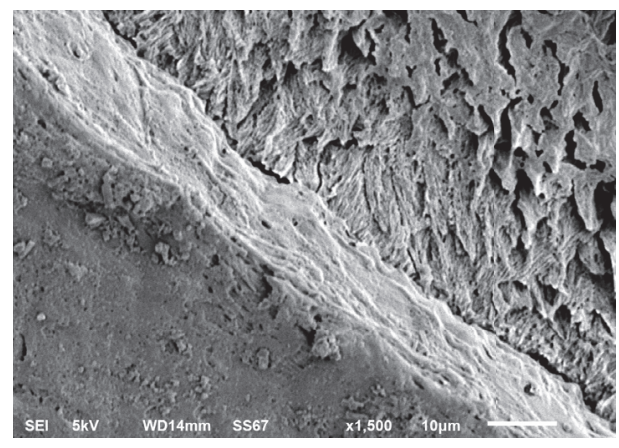

(b)

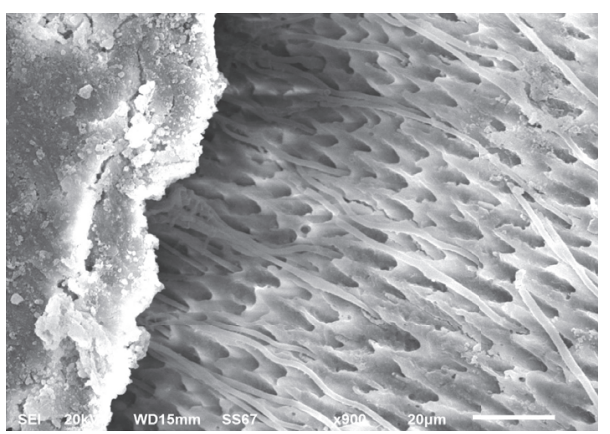

(c)

FIGURE 7: MEB microphotography of moderate fluorosis dentin-resin interface treated with the following techniques: (a) self-etch primer (SE), (b) pretreatment sodium hypochlorite commercial and self-etch primer ( $\mathrm{NaOCl} / \mathrm{SE})$, and (c) pretreatment sodium hypochlorite commercial and self-etch primer with silver nanoparticles $(\mathrm{NaOCl} / \mathrm{SE}+\mathrm{NaAg})$. 


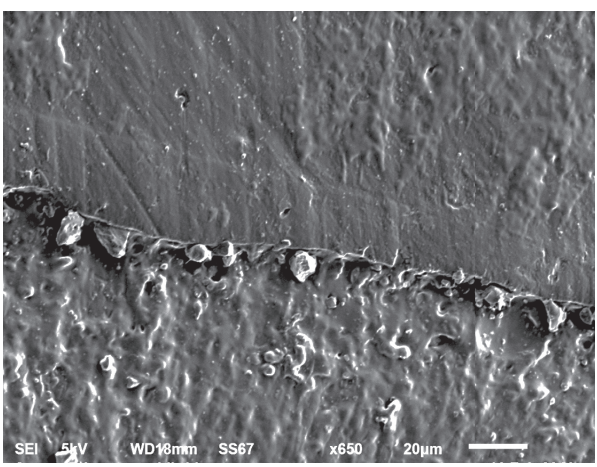

(a)

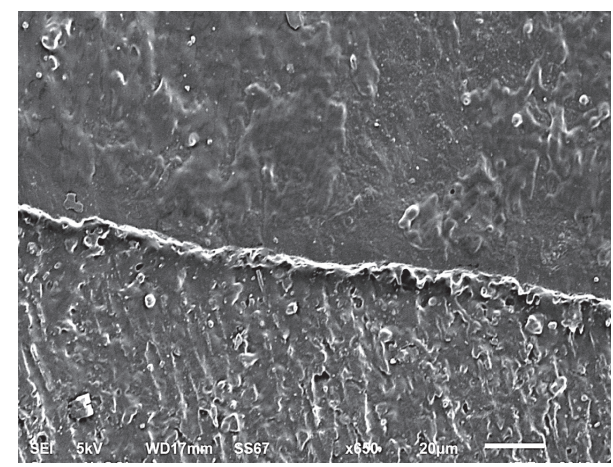

(b)

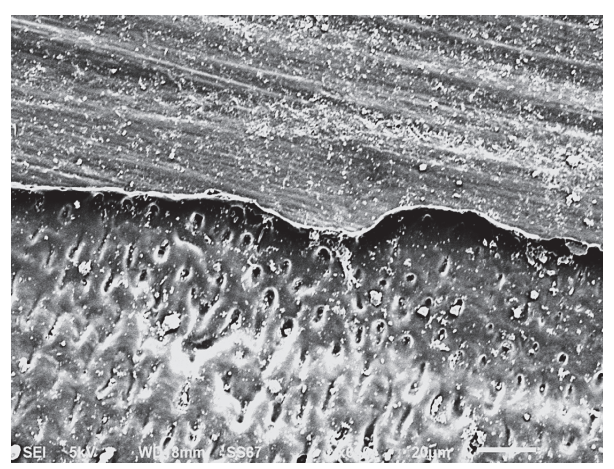

(c)

FIGURE 8: MEB microphotography of severe fluorosis dentin-resin interface treated with the following techniques: (a) self-etch primer (SE), (b) pretreatment sodium hypochlorite commercial and self-etch primer $(\mathrm{NaOCl} / \mathrm{SE})$, and (c) pretreatment sodium hypochlorite commercial and self-etch primer with silver nanoparticles $(\mathrm{NaOCl} / \mathrm{SE}+\mathrm{NaAg})$.

microscopy mention that the microstructural characteristics of dentinal substrate in affected dentin have a different behavior; since the sclerotic dentin has a significantly higher resistance to the action of orthophosphoric acid, the fluorotic dentin can be compared with it; both have lower density in dentinal tubules and this affected their micromorphology [20]. According to our results, fluorotic dentin has a tendency to present lower roughness values than healthy dentin when treated with the control subgroup (conventional system of two-step self-etching) although there was no statistically significant difference; Zavala-Alonso et al. reported that roughness increases with the degree of severity of fluorosis when a total etch system was applied on healthy and fluorotic dentin [17]; the differences in this study and ours can be explained because, using a self-etching system, smear layer is not washed and can create a smoother surface since it is wet by the primer of the system used at the time of reading. In the images obtained through AFM we can observe different micromorphology that shows the fluorotic dentin, having greater disruption of the surface when increasing severity of dental fluorosis; this may be because this substrate has greater amount of intertubular dentin and its hydroxyapatite crystals are modified morphologically; due to this pattern amorphous and low mineral content, demineralization patterns are modified [21].

On the other hand, the sodium hypochlorite has been used as a dentin deproteinizing agent, this is well known as a nonspecific proteolytic agent, for its ability to remove organic matter as well as magnesium and carbonate ions [22] at the same time. Silver nanoparticles are important antibacterial agents which have been shown to have an antimicrobial longterm effect [23]; therefore, an etching system antibacterial could be beneficial because the primer in direct contact with infiltrates dentinal tubules helps to disinfect the prepared tooth cavity and eradicate residual bacteria. In our results of atomic force microscopy although there was no significant statistical difference, it was demonstrated that the roughness value of healthy dentin was higher in subgroup 1 than in subgroups 2 and 3; however, fluorotic dentine shows higher roughness values in subgroups 2,3, and 4 in comparison with the control subgroup, even though statistically significant differences were not found; this may be because an amount of organic matter is removed and the substrate is more susceptible to demineralization caused by the self-etching agent [24-27]. Fawzy et al. in 2008 [28] reported roughness values in pretreated dentin with sodium hypochlorite comparing the total etch system with self-etching, obtaining the highest values in the total etch system; it is worth mentioning that the application time of sodium hypochlorite in that study was 120 seconds, washing and drying, while, in our study, only pretreatment was active and dried with absorbent paper, but these results are comparable to ours.

Silver nanoparticles have been developed with the purpose of reducing bacterial adhesion to dental materials, Due 
to this, they were added to the system self-etching silver nanoparticles of $10 \mathrm{~nm}$ since according to Espinosa-Cristóbal et al. [23] smaller particle size will achieve greater bactericidal effect against cariogenic bacteria like Streptococcus mutans; a concentration of $0.05 \% \mathrm{w} / \mathrm{v} \mathrm{NaAg}$ was used, as some studies report low cytotoxicity with high viability of human periodontal fibroblasts and directed effect and sustained release in the implantation site [29]. In subgroup 3 of the groups of mild and moderate fluoride dentin, it was observed that the roughness values tended to increase in comparison to subgroups 1 and 2, although the differences were not statistically significant; this trend was not observed in the dentin group with severe fluorosis since the roughness values in subgroup 3 tended to decrease compared to subgroups 1 and 2, although again no statistically significant differences were found. A probable explanation for what is found in the group of severe dentine is that it has a higher degree of pathological involvement in their micromorphology; once done, the dentin pretreatment and demineralization subsequent with silver nanoparticles create mineral percentage decompensation owing to high hypomineralization already present $[30,31]$ and this could make fewer calcium ions that were removed not available in dentin hypomineralized for attachment with the carboxyl groups of the restoration $[32,33]$. It is also very likely that it was a deposit of silver nanoparticles in the dentinal tubules which might have manifested with low permeability and smaller diameter of this dental substrate.

When comparing our roughness results with microtensile values, it is observed that although there is a trend of greater roughness in subgroups 2 and 3 in mild and moderate dentin, in the microtension test the adhesion strength with these techniques and the values decrease of healthy dentin with the built-in silver nanoparticle technique is higher and more acceptable at the clinical level; these results can be explained based on the fluorosis pattern decreasing the area of surface tension in its micromorphology and the degree of wettability produced by self-etching. However, our results agree with those of Spazzin et al. in 2009 [34], reporting on treated dentin with $\mathrm{NaOCl}$ average $\mu \mathrm{TBS}$ of 17.8 and $19.2 \mathrm{MPa}$. In our study was obtained average $\mu$ TBS of $15.62 \mathrm{MPa}$ which we attribute to a longer storage time of the samples used, it was determined to get closer to clinical reality, and some reports mention the importance of type and storage time of the samples in the result of the adhesion strength. This can greatly influence the results because there is an enzymatic degradation in the interface with the passage of time [35], as well as percentage and mode of application of $\mathrm{NaOCl}$, since in the present study it was placed at 5.25\% and actively [36] and it was applied at $10 \%$ with a passive technique. It has been determined that, for the removal of organic matter and collagen fibers in the dentin, application of $5.25 \% \mathrm{NaOCl}$ for 1 minute is sufficient. There are some other reports with tensile values ranging from 4.68 to $7.42 \mathrm{MPa}$, influencing the result of the sample area to be tested to obtain these minor parameters [35], wherein total etch system and self-etch are compared but are applied by pretreating $5.25 \% \mathrm{NaOCl}$ for 2 minutes [37]. Further another report mentions that $\mathrm{NaCl}$ can have some effect on free radicals, upon release, and not allow proper polymerization of the adhesive system [38]. Our results show a mode of failure predominantly adhesive; this is of great importance since in the cohesive and mixed faults the fracture of the dental substrate intervenes, causing with this not to preserve dental structure. The group that presents a greater number of cohesive faults (23\%) was dentine with fluorosis, perhaps due to the great hypomineralization and greater protein quantity that presents this affected tissue, emphasizing the group of moderate fluorosis with dentin pretreatment (13\%). Although dentin pretreatment with sodium hypochlorite deproteinizes and demineralizes, the results found suggest that in the group with pretreatment and silver nanoparticles it was helped to promote the remineralization of the dentin structure [39]. These results agree with Koshiro et al. [35]; they do mention that the smaller the cross section area of a material, the lower the incorporation of defects, since this acts as an area of tensions and therefore area of fracture propagation, just like that in the microtensile test where there is better stress distribution leading to low incidence of cohesive failure, although these are still produced [40], as seen in the photomicrographs of SEM where hybrid areas or discontinuance of the hybrid layer was observed because the samples are larger than those subjected to the microtensile test and only some groups could observe a complete continuity, but without resinous extensions within the dentinal tubules because of the amount of smear layer potentially present on the peri- and intertubular dentin. It is very recommendable to analyze the surface of different substrates since micromorphological characteristics of teeth with any pathology in different area or depth change [41] and also will be modified with the type of treatment to be performed on this and this can influence directly the formation of the hybrid layer and its proper adhesion, which will reflect the success to short or long term of the final restoration.

The incorporation of silver nanoparticles to the adhesive system for the healthy group (22.37 MPa) showed a slight improvement not statistically significant in adhesive strength when compared among the other subgroups (SE control 15.62, $\mathrm{NaOCl}+\mathrm{SE} \mathrm{11.30}$, and $\mathrm{NaOCl}+\mathrm{SE}-\mathrm{NaAg} 22.37)$, since the silver nanoparticles are water-based and render the self-etching primer more hydrophilic, providing a suitable chemical change to create an increase in the surface tension of the dentin substrate and in this way adequately penetrate the resinous monomer of the adhesive system. Additional research is needed on the behavior of silver nanoparticles and their interaction within the long-term dentinal tubule. The hypothesis of the study is rejected since no statistically significant differences were found that show that the dentin pretreatment with $5.25 \%$ sodium hypochlorite and the incorporation of $\mathrm{NaAg}$ to the self-etching system improve the topography, mechanical, and adhesive properties of the dentin affected by fluorosis.

\section{Conclusions}

Our results suggest that dentin pretreatment technique with $5.25 \% \mathrm{NaOCl}$ and the incorporation of $\mathrm{NaAg}$ to the self-etch adhesive system cannot produce a surface suitable for a better 
adhesion or reduce adhesive failures. It is of great importance to point out that there are not enough studies about adhesion systems to fluorotic dentin and that the continuation of this type of studies would be of great benefit for the development of new materials for this group of teeth vulnerable to adhesion and greater propensity for secondary caries.

\section{Conflicts of Interest}

The authors declare that there are no conflicts of interest regarding the publication of this paper.

\section{References}

[1] P. K. Den Besten, "Dental fluorosis: its use as a biomarker," Advances in Dental Research, vol. 8, no. 1, pp. 105-110, 1994.

[2] J. J. Murray, A. J. Rugg-Gunn, and G. N. Jenkins, Fluoride in Caries Prevention, Butterworth-Heinemann Ltd., Oxford, UK, 3rd edition, 1991.

[3] D. C. Clark, "Trends in prevalence of dental fluorosis in North America," Community Dentistry And Oral Epidemiology, vol. 22, no. 3, pp. 148-152, 1994.

[4] A. K. Mascarenhas, "Risk factors for dental fluorosis: a review of the recent literature," Pediatric Dentistry, vol. 22, no. 4, pp. 269-277, 2000.

[5] D. G. Pendrys, "Risk of enamel fluorosis in nonfluoridated and opimally fluoridated populations: considerations for the dental professional," Journal of the American Dental Association, vol. 131, no. 6, pp. 746-755, 2000.

[6] P. K. Denbesten and H. Thariani, "Biological mechanisms of fluorosis and level and timing of systemic exposure to fluoride with respect to fluorosis," Journal of Dental Research, vol. 71, no. 5, pp. 1238-1243, 1992.

[7] U. Kierdorf, H. Kierdorf, and O. Fejerskov, "Fluoride-induced developmental changes in enamel and dentine of European roe deer (Capreolus capreolus L.) as a result of environmental pollution," Archives of Oral Biology, vol. 38, no. 12, pp. 1071-1081, 1993.

[8] O. Fejerskov, J. A. Yaeger, and A. Thylstrup, "Microradiography of the effect of acute and chronic administration of fluoride on human and rat dentine and enamel," Archives of Oral Biology, vol. 24, no. 2, pp. 123-130, 1979.

[9] P. G. K. Waidyasekera, T. Nikaido, D. D. S. Weerasinghe, K. A. Wettasinghe, and J. Tagami, "Caries susceptibility of human fluorosed enamel and dentine," Journal of Dentistry, vol. 35, no. 4, pp. 343-349, 2007.

[10] D. S. Weerasinghe, T. Nikaido, K. A. Wettasinghe, J. B. Abayakoon, and J. Tagami, "Micro-shear bond strength and morphological analysis of a self-etching primer adhesive system to fluorosed enamel," Journal of Dentistry, vol. 33, no. 5, pp. 419426, 2005.

[11] P. G. K. Waidyasekera, T. Nikaido, D. D. S. Weerasinghe, and J. Tagami, "Bonding of acid-etch and self-etch adhesives to human fluorosed dentine," Journal of Dentistry, vol. 35, no. 12, pp. 915-922, 2007.

[12] K. Zhang, M. A. S. Melo, L. Cheng, M. D. Weir, Y. Bai, and H. H. K. Xu, "Effect of quaternary ammonium and silver nanoparticle-containing adhesives on dentin bond strength and dental plaque microcosm biofilms," Dental Materials, vol. 28, no. 8, pp. 842-852, 2012.
[13] K. Zhang, L. Cheng, S. Imazato et al., "Effects of dual antibacterial agents MDPB and nano-silver in primer on microcosm biofilm, cytotoxicity and dentine bond properties," Journal of Dentistry, vol. 41, no. 5, pp. 464-474, 2013.

[14] K. Zhang, F. Li, S. Imazato et al., "Dual antibacterial agents of nano-silver and 12-methacryloyloxydodecylpyridinium bromide in dental adhesive to inhibit caries," Journal of Biomedical Materials Research Part B: Applied Biomaterials, vol. 101, no. 6, pp. 929-938, 2013.

[15] F. Torres-Méndez, G.-A. Martinez-Castañon, I. Torres-Gallegos et al., "Effects of silver nanoparticles on the bonding of three adhesive systems to fluorotic enamel," Dental Materials Journal, vol. 36, no. 3, pp. 266-274, 2017.

[16] L. F. Espinosa-Cristóbal, G. A. Martínez-Castañón, R. E. Martínez-Martínez, J. P. Loyola-Rodríguez, J. F. Reyes-Macías, and F. Ruiz, "Antibacterial effect of silver nanoparticles against Streptococcus mutans," Materials Letters, vol. 63, no. 29, pp. 2603-2606, 2009.

[17] V. Zavala-Alonso, R. Aguilera-Flores, N. Patiño-Marin, G. A. Martinez-Castañon, K. J. Anusavice, and J. P. Loyola-Rodriguez, "Nanostructure evaluation of healthy and fluorotic dentin by atomic force microscopy before and after phosphoric acid etching," Dental Materials Journal, vol. 30, no. 4, pp. 546-553, 2011.

[18] M. Peumans, P. Kanumilli, J. De Munck, K. Van Landuyt, P. Lambrechts, and B. van Meerbeek, "Clinical effectiveness of contemporary adhesives: a systematic review of current clinical trials," Dental Materials, vol. 21, no. 9, pp. 864-881, 2005.

[19] M. Brännström and K. J. Nordenvall, "The effect of acid etching on enamel, dentin, and the inner surface of the resin restoration: a scanning electron microscopic investigation," Journal of Dental Research, vol. 56, no. 8, pp. 917-923, 1977.

[20] A. Georgescu, G. Iovan, S. Stoleriu, C. Topoliceanu, and S. Andrian, "Atomic force microscopy study regarding the influence of etching on affected and sclerotic dentine," Romanian Journal of Morphology and Embryology, vol. 51, no. 2, pp. 299302, 2010.

[21] M. Okazaki and M. Sato, "Computer graphics of hydroxyapatite and $\beta$-tricalcium phosphate," Biomaterials, vol. 11, no. 8, pp. 573-578, 1990.

[22] T. Sakae, H. Mishima, and Y. Kozawa, "Changes in bovine dentin mineral with sodium hypochlorite treatment," Journal of Dental Research, vol. 67, no. 9, pp. 1229-1234, 1988.

[23] L. F. Espinosa-Cristóbal, G. A. Martinez-Castanon, E. J. Téllez-Déctor, N. Niño-Martínez, N. V. Zavala-Alonso, and J. P. Loyola-Rodríguez, "Adherence inhibition of Streptococcus mutans on dental enamel surface using silver nanoparticles," Materials Science and Engineering C Mater Biol Appl., vol. 33, no. 4, pp. 2197-2202, 2013.

[24] S. Kunawarote, M. Nakajima, R. M. Foxton, and J. Tagami, "Effect of pretreatment with mildly acidic hypochlorous acid on adhesion to caries-affected dentin using a self-etch adhesive," European Journal of Oral Sciences, vol. 119, no. 1, pp. 86-92, 2011.

[25] M. A. Montes, M. F. de Goes, and M. A. Sinhoreti, "The in vitro morphological effects of some current pre-treatments on dentin surface: a SEM evaluation," Operative Dentistry, vol. 30 , no. 2 , pp. 201-212, 2005.

[26] G. Taniguchi, M. Nakajima, K. Hosaka et al., "Improving the effect of $\mathrm{NaOCl}$ pretreatment on bonding to caries-affected dentin using self-etch adhesives," Journal of Dentistry, vol. 37, no. 10, pp. 769-775, 2009. 
[27] G. Mountouris, N. Silikas, and G. Eliades, "Effect of sodium hypochlorite treatment on the molecular composition and morphology of human coronal dentin," Journal of Adhesive Dentistry, vol. 6, no. 3, pp. 175-182, 2004.

[28] A. S. Fawzy, M. A. Amer, and F. S. El-Askary, "Sodium hypoclorite as dentin pretreatment for etch-and-rise singlebottle and two-step self-estching adhesives: atomic forcé microscope and tensile bond strength evaluation," The journal of adhesive dentistry, vol. 10, no. 2, pp. 135-144, 2008.

[29] J. F. Hernández-Sierra, O. Galicia-Cruz, A. Salinas-Acosta, F. Ruíz, M. Pierdant-Pérez, and A. Pozos-Guillén, "In vitro cytotoxicity of silver nanoparticles on human periodontal fibroblasts," Journal of Clinical Pediatric Dentistry, vol. 36, no. 1, pp. 37-42, 2011.

[30] E. S. Akpata, Z. Fakiha, and N. Khan, "Dental fluorosis in 12-15year-old rural children exposed to fluorides from well drinking water in the Hail region of Saudi Arabia," Community Dentistry and Oral Epidemiology, vol. 25, no. 4, pp. 324-327, 1997.

[31] W. Y. Awliya and E. S. Akpata, "Effect of fluorosis on shear bond strength of glass ionomer-based restorative materials to dentin," The Journal of Prosthetic Dentistry, vol. 81, no. 3, pp. 290-294, 1999.

[32] B. E. Causton, "Improved bonding of composite restorative to dentine. A study in vitro of the use of a commercial halogenated phosphate ester," British Dental Journal, vol. 156, no. 3, pp. 9395, 1984.

[33] J. Perdigão, S. Eiriksson, B. T. Rosa, M. Lopes, and G. Gomes, "Effect of calcium removal on dentin bond strengths," Quintessence International, vol. 32, no. 2, pp. 142-146, 2001.

[34] O. Spazzin Aloísio, D. Galafassi, S. Gonçalves Luciano, R. Moraes Rafael, and Carlini-Júnior B., "Bonding to wet or dry deproteinized dentin: microtensile bond strength and confocal laser micromorphology analysis," Brazilian Journal of Oral Sciences, vol. 8, pp. 1-5, 2009.

[35] K. Koshiro, S. Inoue, H. Sano, J. De Munck, and B. Van Meerbeek, "In vivo degradation of resin-dentin bonds produced by a self-etch and an etch-and-rinse adhesive," European Journal of Oral Sciences, vol. 113, no. 4, pp. 341-348, 2005.

[36] P. Taweesak, N. Masatoshi, M. Foxtonc Richard, and J. Tagamid, "Scrubbing effect of self-etching adhesives on bond strength to NaOCl-treated dentin," The journal of adhesive dentistry, vol. 14, no. 2, pp. 121-127, 2012.

[37] D. H. Pashley, H. Sano, B. Ciucchi, M. Yoshiyama, and R. M. Carvalho, "Adhesion testing of dentin bonding agents: a review," Dental Materials, vol. 11, no. 2, pp. 117-125, 1995.

[38] F.-S. Aguilera, R. Osorio, E. Osorio, P. Moura, and M. Toledano, "Bonding efficacy of an acetone/based etch-and-rinse adhesive after dentin deproteinization," Medicina Oral, Patologia Oral y Cirugia Bucal, vol. 17, no. 4, pp. 649-654, 2012.

[39] M. A. S. Melo, S. F. F. Guedes, H. H. K. Xu, and L. K. A. Rodrigues, "Nanotechnology-based restorative materials for dental caries management," Trends in Biotechnology, vol. 31, no. 8, pp. 459-467, 2013.

[40] F. R. Tay and D. H. Pashley, "Aggressiveness of contemporary self-etching systems. I. Depth of penetration beyond dentin smear layers," Dental Materials, vol. 17, no. 4, pp. 296-308, 2001.

[41] R. Harris and C. J. Griffin, "The ultrastructure of small blood vessels of the normal human dental pulp," Australian Dental Journal, vol. 16, no. 4, pp. 220-226, 1971. 

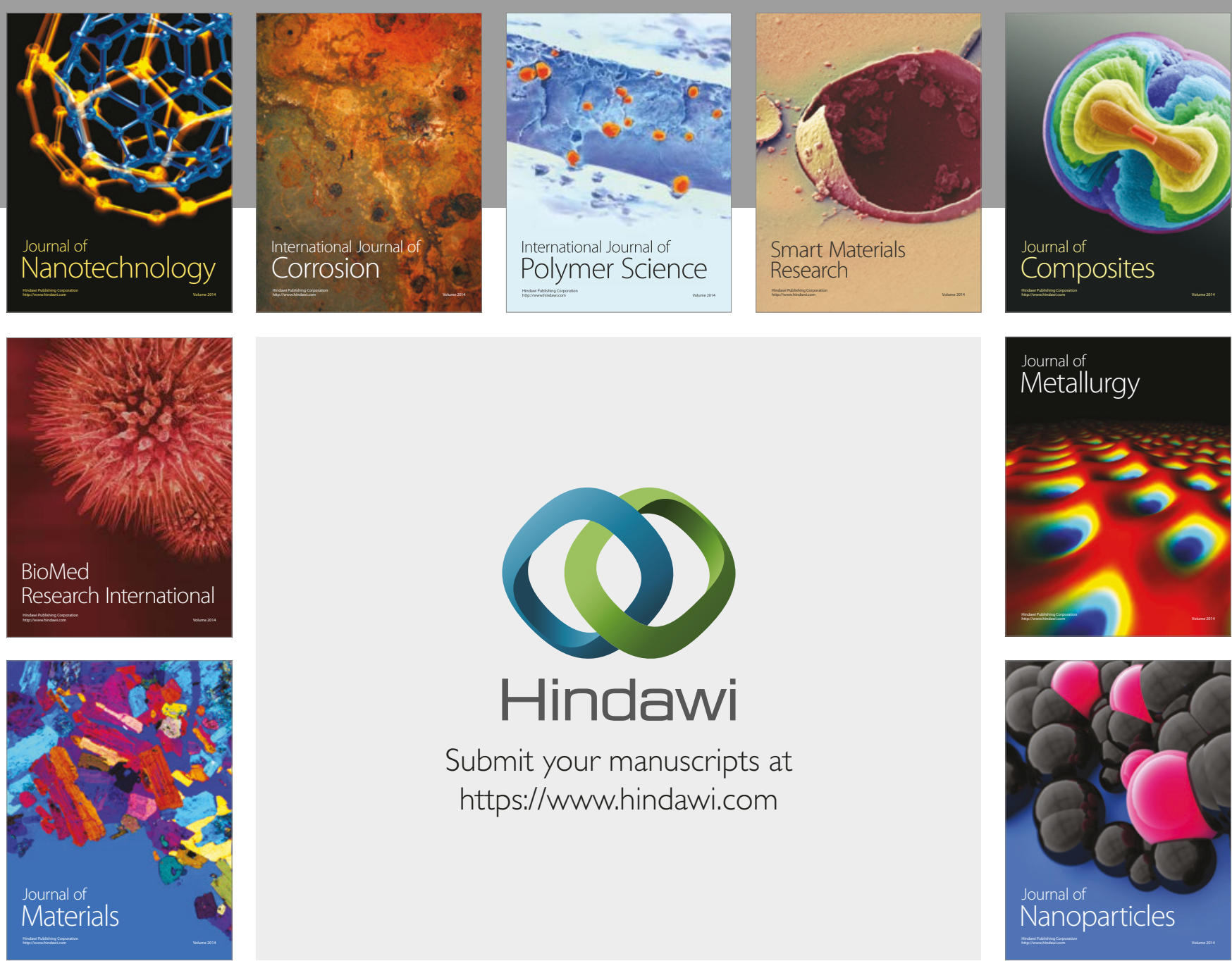

\section{Hindawi}

Submit your manuscripts at

https://www.hindawi.com
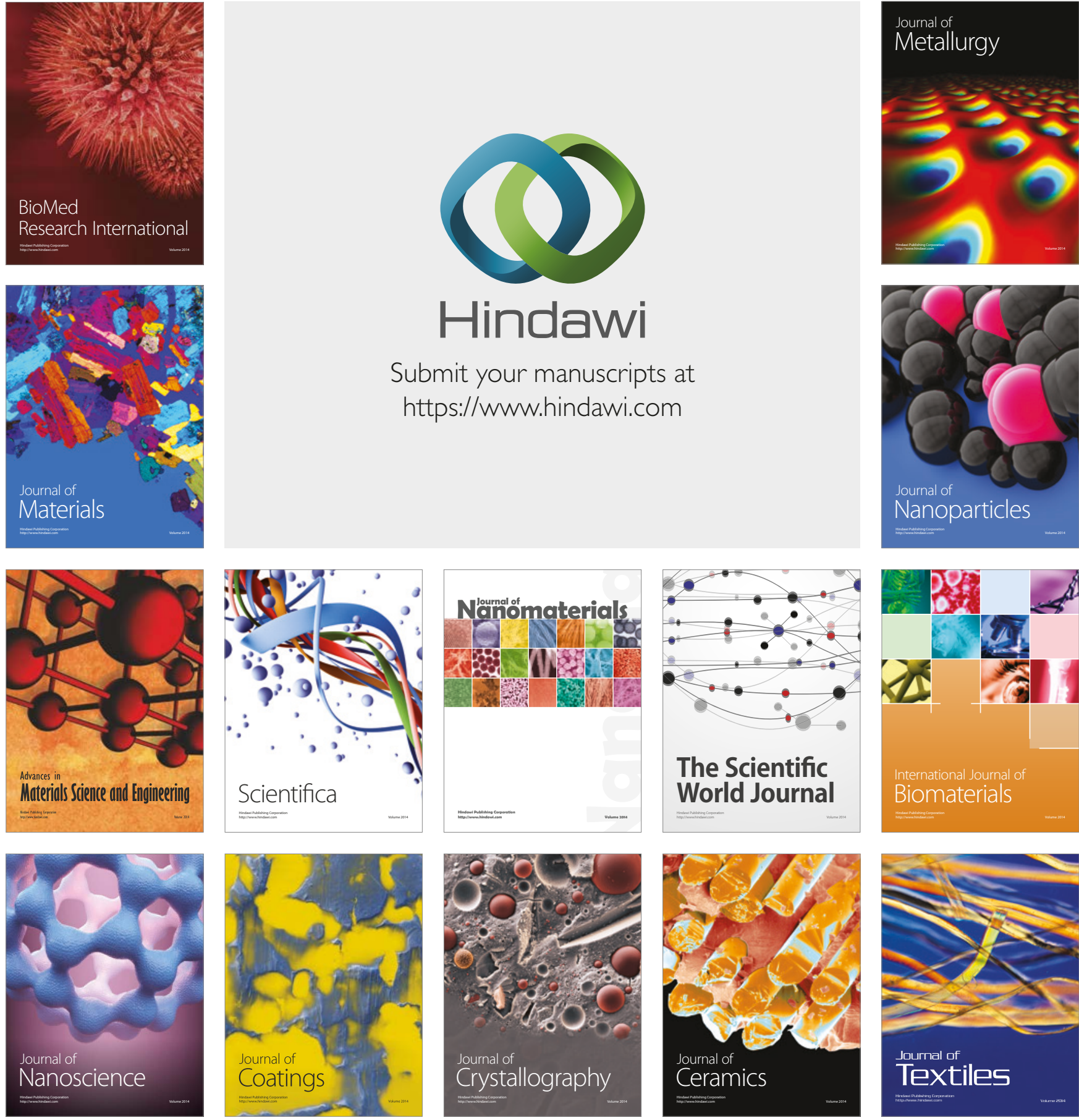

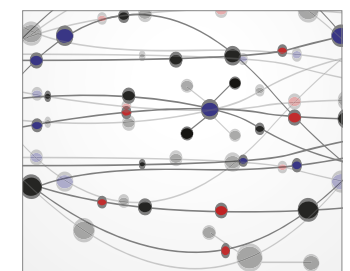

The Scientific World Journal
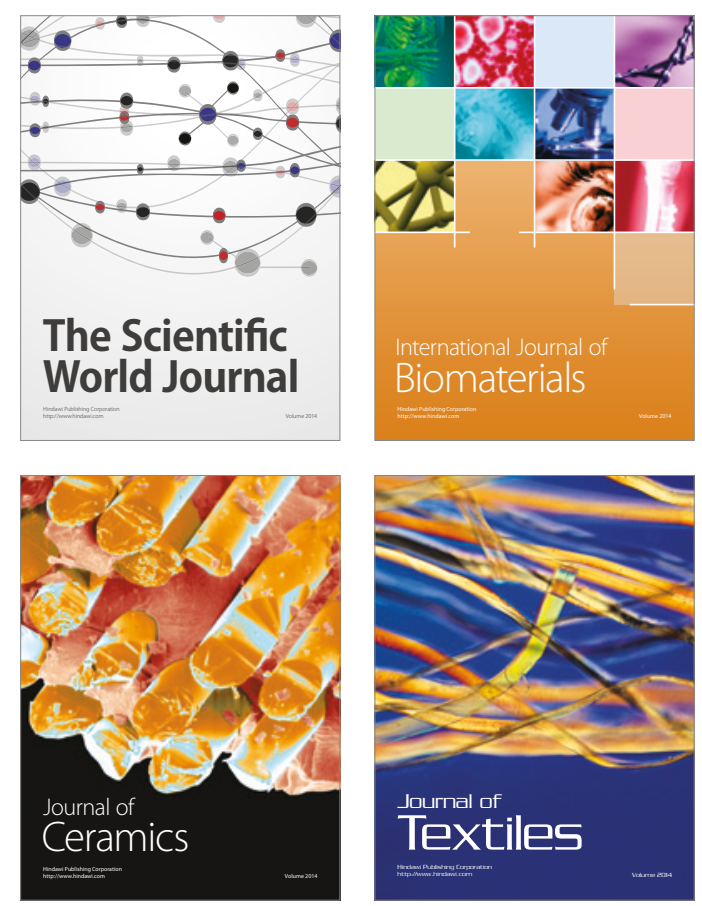